ORIGINAL ARTICLE

AFRICAN JOURNAL OF CLINICAL AND EXPERIMENTAL MICROBIOLOGY ISBN 1595-689X MAY 2018 VOL19 No.2

AJCEM/1813

COPYRIGHT 2018 https://dx.doi.org/10.4314/ajcem.v19i2.3

AFR. J. CLN. EXPER. MICROBIOL. 19 (2): 88-92

\title{
SERUM AND SPUTUM SURFACTANTS -A AND -D IN MULTIDRUG-RESISTANT AND DRUG- SENSITIVE TUBERCULOSIS PATIENTS
}

Onifade, A.A, Edem, V.F and Arinola, O.G*

Department of Chemical Pathology, College of Medicine, University of Ibadan, Nigeria

*Correspondence: Arinola O.G.

\begin{abstract}
Abnormal production and function of surfactants are associated with pulmonary diseases. Also, pulmonary infections alter surfactant metabolism. Due to lack of information on the levels of surfactants A (SP-A) and D (SP-D) in Nigerian tuberculosis (TB) patients, this study assessed these surfactants in both sputum and serum of drug sensitive- and multidrug resistant- TB patients using ELISA. The aim is to explore the diagnostic or therapeutic potential of SP-A and SP-D in TB patients. Also, to find out appropriate sample for the analyses of SP-A and SP-D in TB patients.

The mean serum levels of SP-A and SP-D were not significantly reduced in MDR-TB $(n=30)$ and DS-TB patients $(n=30)$ compared with non-TB apparently healthy controls $(n=30)(p>0.05)$. Mean sputum levels of SP-A and SP-D were significantly reduced in DS-TB patients compared with the levels in MDR-TB patients $(p<0.05)$. These findings suggest that the sputum SP-D and SP-A levels but not serum SP-D and SP-A levels are useful indicators of the disease activity in pulmonary TB patients.
\end{abstract}

Keywords: Tuberculosis, Surfactants, Diagnosis, Nigeria

\section{LES TAUX SÉRIQUES D'EXPECTORATIONS ET SANS TENSIOACTIFS- A ET D DANS LA TUBERCULOSE MULTIRÉSISTANTE ET LA TUBERCULOSE CHEZ LES PATIENTS SENSIBLES}

\author{
Onifade, A.A, Edem, VF et Arinola, O.G*
}

Département de pathologie chimique, Collège de médecine, Université d'Ibadan, Nigeria *Correspondance : Arinola O.G.

Résumé

production anormale et la fonction d'agents tensio-actifs sont associés à des maladies pulmonaires. En outre, les infections pulmonaires modifier le métabolisme du surfactant. En raison du manque d'informations sur les niveaux d'agents de surface A (SP-A) et D (SP-D) in Nigerian la tuberculose (TB) patients, cette étude a évalué ces surfactants dans les expectorations et le sérum de la multirésistance et sensible-- patients atteints de tuberculose à l'aide d'ELISA. L'objectif est d'explorer les possibilités diagnostiques ou thérapeutiques de SP-A et SP-D dans les patients atteints de tuberculose. Aussi, nous avons voulu en savoir échantillon approprié pour l'analyse de SP-A et SP-D dans les patients atteints de tuberculose.

Les niveaux sériques de SP-A et SP-D n'ont pas été significativement réduite dans la TB-MR $(n=30)$ et DS-TB patients $(n$ $=30)$ par rapport aux non-contrôles apparemment en bonne santé $(n=30)(p>0,05)$. Les niveaux d'expectorations de SP-A et SP-D ont été significativement réduits dans DS-tuberculeux par rapport aux niveaux de la multirésistance patients $(p<$ $0,05)$. Ces résultats suggèrent que l'expectoration SP-D et SP-A mais pas la SP-D et SP-A sont des indicateurs utiles à l'activité de la maladie chez les patients atteints de tuberculose pulmonaire.

Mots clés : $\quad$ Tuberculose, surfactants, le diagnostic, $\quad$ le Nigeria

\section{INTRODUCTION}

Mycobacterium tuberculosis (M.tb) is a facultative intracellular pathogen that infects humans causing tuberculosis $(1,2)$. Inhalation of infectious aerosols is the common route of transmission and it is finally deposited in the terminal bronchioles and alveoli of the lungs (3). At this early stage of infection, interactions of $M . t b$ with the innate immune environment of the lung have been proposed to determine the outcome and progression of $M$.tb infection (2). However, such interactions are incompletely known. One of the first interactions of $M . t b$ in the lung is the binding is pulmonary surfactant molecules, which are multi-molecular complexes composed of lipids and proteins secreted by alveolar type II cells and Clara cells in distal bronchioles $(4,5)$.

Four specific surfactant proteins have been identified viz: surfactant protein SP-A, SP-B, SP-C and SP-D. SP-B and SP-C have been characterized as hydrophobic polypeptides that enhance the adsorption of lipid to the surface of the alveoli (6). 
On the other hand SP-A and SP-D are hydrophilic and participate in the innate host defense immune system. SP-D binds to macrophages and neutrophils and promotes phagocytosis and killing of bacteria, fungi, and viruses (7). SP-A and SP-D lines the lungs and are essential for pulmonary function by reducing surface tension (57). SP-A and SP-D also play important roles in innate immune responses to a wide range of respiratory pathogens including $M . t b(8-15)$. Additionally, it has been shown that pulmonary SPD contributes significantly to host control of infections by the parasitic helminth Nippostrongylus brasiliensis (16).

Binding of pathogens by SP-A and SP-D trigger various immune responses, including opsonisation leading to enhanced phagocytosis and killing by recruited macrophages and neutrophils via oxidative mechanisms, aggregation of pathogens thereby hindering their entry into host cells, and direct microbicidal activities by increasing cellular membrane permeability (17). SPs also assist in the clearance of apoptotic cells and in modulating inflammation (18). The interaction of SPs with immune cells to initiate clearance mechanisms is mediated by SP's collagen region with a number of proposed receptor molecules on these cells (19).

Considering the intricate relationship between SP-A and SP-D with innate immune cells necessary to control respiratory pathogens, the present study thus determined both serum and sputum levels of SP-A and SP-D in DS-TB and MDR-TB, which were not previously studied among Nigerian TB patients.

\section{MATERIALS AND METHODS}

A total of 90 participants were enrolled for this study. This comprised of thirty (30) multi-drug resistant TB (MDR-TB) patients, thirty (30) drugsensitive TB (DS-TB) patients and thirty (30) non-TB apparently healthy controls. MDR-TB patients had been previously diagnosed as being infected with isoniazid and rifampicin resistant strains of Mycobacterium tuberculosis (Mtb) using clinical history, Chest X-ray and GENE Xpert. These patients were admitted into the MDR-TB centre,
University College Hospital (UCH) Ibadan, Nigeria for anti-TB treatment. DS-TB patients were recruited from the Medicine Out-patient Clinic, University College Hospital, Ibadan, Nigeria by a Consultant Chest Physician after confirmation with Microbiological test (sputum smear microscopy), chest X-ray and clinical history. Five milliliters (5 $\mathrm{ml}$ ) of blood was drawn from the antecubital vein of each participant and dispensed into sterile plain sample tubes without anticoagulant. Blood was centrifuged at $1000 \mathrm{~g}$ for $15 \mathrm{mins}$ and serum was obtained. Serum was stored at $-20^{\circ} \mathrm{C}$ until analysis. Spot collection of sputum sample was carried out. Study participants were asked to rinse their mouth with water to reduce salivary contamination of sputum. Sputum produced was collected into $20 \mathrm{ml}$ sterile disposable polypropylene tubes and kept on ice from collection to arrival at the laboratory. Sputum sample was homogenized with an equal volume of phosphate buffered saline (PBS). Homogenate was centrifuged at $10,000 \mathrm{~g}$ for 10 minutes to remove cellular debris and mucus, and supernatant obtained was stored at $-20^{\circ} \mathrm{C}$ until analysis. Enzyme Linked Immunosorbent Assay (ELISA) method was used for the determination of serum and sputum concentrations of surfactantassociated protein A (SP-A) and Surfactantassociated protein D (SP-D) as previously carried out (20).

\section{RESULTS}

As shown in the Table, the mean serum levels of SPA were not significantly reduced in MDR-TB patients and DS-TB patients compared with control while the mean serum levels of SP-D were not significantly raised in MDR-TB patients and DS-TB patients compared with control. The mean sputum levels of SP-A was significantly reduced in DS-TB patients compared with MDR-TB patients and control while the mean sputum levels of SP-D were significantly raised in DS-TB patients and MDR-TB patients compared with control. Also, the mean sputum level of SP-D was significantly raised in MDR-TB patients compared with DS-TB patients.

TABLE 1: COMPARISON OF MEAN LEVELS OF SPUTUM AND SERUM SP-A (NG/L) AND SP-D (PG/ML) IN MDR-TB, DS-TB AND CONTROL

\begin{tabular}{lllllll}
\hline Variables & MDR-TB & DS-TB & Control & $\mathrm{p}^{\prime}$ & $\mathrm{p}^{\prime \prime}$ & $\mathrm{p}^{\prime \prime}$ \\
\hline Serum SP-A & $306.90 \pm 133.32$ & $344.66 \pm 139.87$ & $368.72 \pm 210.37$ & 0.361 & 0.725 & 0.455 \\
Sputum SP-A & $503.22 \pm 170.25$ & $312.03 \pm 187.98$ & $570.15 \pm 175.43$ & 0.326 & $0.001^{*}$ & $0.007^{*}$ \\
Serum SP-D & $1709.38 \pm 665.56$ & $1701.31 \pm 596.96$ & $1547.34 \pm 324.58$ & 0.448 & 0.430 & 0.972 \\
Sputum SP-D & $3596.45 \pm 636.45$ & $2600.0 \pm 1085.04$ & $1210.57 \pm 457.39$ & $0.000^{*}$ & $0.000^{*}$ & $0.005^{*}$ \\
\hline
\end{tabular}

p' MDR-TB compared with control; p" DS-TB compared with control; p"' MDR-TB compared with DS-TB

*Significant at $\mathrm{p}<0.05$ 


\section{DISCUSSION}

Tuberculosis which claims at least 3 million lives annually is caused by M.tb $(1,2)$. The interaction between $M . t b$ and the pulmonary lining represents the initial contact of the bacterium with the host immune system (1-3), thus the factors which affect phagocytosis of M.tb by host immune cells are important to our understanding of disease pathogenesis. Surfactant and its associated proteins, in conjunction with alveolar macrophages, are important components of the pulmonary alveoli. Surfactant proteins (SP-A, SP-B, SP-C, and SP-D) are enriched with a relatively unique phospholipid (dipalmitoylphosphatidylcholine) $(3,4)$. The main functions of surfactant are lowering surface tension at the air-liquid interface and thus preventing alveolar collapse at end-expiration, interacting with and subsequent killing of pathogens or preventing their dissemination and modulating immune responses (5-7).Two major surfactant associated proteins, surfactant protein A (SP-A) and surfactant protein D (SP-D), contain carbohydrate recognition domains (CRDs) (3-7).

SP-A binds with lipopolysaccharides and peptidoglycan derived from $K$. pneumoniae, $E$. coli, $P$. aeruginosa and Legionella pneumophila, Staphylococcus aureus and Streptococcus pneumoniae as well as Mycobacterium avium, Mycobacterium tuberculosis and Mycoplasma pneumoniae which consequently result in agglutination, enhancement of pathogen uptake, and growth inhibition (8-15). The metabolism of SP-A in TB patients considered for this study might account for reduced levels of SP-A especially in the sputum which is a transmission medium for M.tb. This may be to agglutinate $M t . b$ in local environment. This hypothesis is supported by a previous study (21) which reported that human SP-A enhances the uptake of the virulent Erdman strain of M.tb by human monocyte-derived macrophages and human alveolar macrophages through direct interaction with the macrophages. The study thus concluded thatSP-A was reported to play a role in the pathogenesis of tuberculosis by enhancing the ability of $M$.tb to enter and survive within its local niche in the host. Another data suggested that SP-A has pleiotropic effects even at the low concentrations found in tuberculosis patients (22). SP-A was reported to augment inflammation in the presence of infection and inhibits inflammation in uninfected macrophages so as to protect uninvolved lung segments from the deleterious effects of inflammation (23). This further support reduced level of SP-A in TB patients as a result of continuous metabolism.

SP-D is synthesized and secreted into the airspaces of the lung by the respiratory epithelium $(4,5)$. At the alveolar level, SP-D is constitutively synthesized and secreted by alveolar type II cells. More proximally in the lung, SP-D is secreted by a subset of bronchiolar epithelial cells, the non-ciliated Clara cells. Because SP-D is stored within the secretory granules of Clara cells $(6,9)$, it seems likely that SP$\mathrm{D}$ is subject to regulated secretion via granule exocytosis at this level of the respiratory tract. In some species, SP-D is also synthesized by epithelial cells and/or submucosal glands associated with the bronchi and trachea (6). This might explain significantly raised sputum levels of SP-D especially in TB patients. SP-D has been reported to agglutinate bacteria, delay phagocytosis and facilitate phagolysosomal fusion (10-12). This explains why SP-D was higher in MDR-TB patients than DS-TB patients considered for this study.

The opposing trends of sputum SP-A (reduced level) and sputum SP-D (raised level) observed in TB patients considered for our study might be related to slight differences in their chemical composition and functions. SP-A preferentially binds monosaccharides and lipid ligands, while SPD additionally binds disaccharides, complex carbohydrates and anionic phospholipids present on cell surfaces (18). This might be explained by subtle structural differences between the CRDs of trimeric SP-A and SP-D resulting in the flatter and more hydrophobic surface of SP-A preferentially binding to less polar substrates, while the more hydrophilic surface of SP-D displays a higher affinity for highly polar targets (24). Moreover, in $\mathrm{SP}-\mathrm{A}$, the Gly-X-Y repeats in the collagenous region are interrupted resulting in a kink (and hence the bunch-like structure) and a relatively smaller distance to the distal CRD compared to SP-D which displays more freedom to bind and aggregate target pathogens (25).

In the case of M. tuberculosis, SP-D has been shown to bind mannosylated lipoarabinomannan (ManLam) from the Erdman strain (26), while SP-A has been shown to bind a wider range of mycobacterial targets, including ManLam (from virulent and avirulent mycobacterial strains) (27), lipomannan (28), a 60-kDa glycoprotein (29), and the M. tuberculosis surface glycoprotein Apa (무). In addition to their carbohydrate specificities, SP-A and SP-D was also reported to differ with respect to several other structural features that determine their interactions with the innate immune system. SP-A forms a bouquet-like 18-mer that associates with surfactant lipids and tubular myosin and can bind to the C1qR receptor, toll-like receptors TLR2 and TLR4, the CD91/calreticulin complex, the signal inhibitory regulatory protein SIRP-alpha, and the unconventional myosin XVIIIA receptor SPR210. SP-D, on the other hand, forms a cross-like dodecamer (12 chains) that resides in the aqueous phase of the alveoli and can bind microfibrilassociated protein 4, CD14, defensins, decorin, C1q, TLR2, TLR4, and a 340-kDa glycoprotein of unknown function (31). 
Exploration of surfactant A therapeutic potential is proposed by the present authors. Animal study and limited human data show that exogenous surfactant decreases DNA synthesis of inflammatory mediators $(32,33)$. Intratracheal administration of a surfactant-amikacin mixture to rats with Pseudomonas pneumonia showed improved anti-inflammatory effects compared with amikacin alone (33). There is also evidence that certain pharmacologic agents may enhance endogenous surfactant levels, although the current data are limited. Antenatal steroids accelerate development

\section{REFERENCES}

1. Flynn, J. L., and J. Chan. 2001. Immunology of tuberculosis. Annu. Rev. Immunol. 19:93-129.

2. North, R. J., and Y. J. Jung. Immunity to tuberculosis. Annu. Rev. Immunol. 2004; 22:599-623.

3. Nicas, M., W. W. Nazaroff, and A. Hubbard. Toward understanding the risk of secondary airborne infection: emission of respirable pathogens. J. Occup. Environ. Hyg. 2005; 2:143-154.

4Voorhout WF, Veenendaal T, Kuroki Y, Ogasawar a $Y$, van

Golde LM, Geuze HJ. Immunocytochemica 1 localization of surfactant protein D (SPD) in type II cells, Clara cells, and alveolar macrophages of rat lung. J Histochem Cytochem. 1992;40:1589-1597.

5. Kalina M, Mason RJ, Shannon JM. Surfactant protein $\mathrm{C}$ is expressed in alveolar type II cells but not in Clara cells of rat lung. Am J Respir Cell Mol Biol. 1992;6:594-600.

6. Crouch E, Wright JR. Surfactant proteins A and D and pulmonary host defense. Annu Rev Physiol. 2001;63:521-554.

7. Crouch E, Hartshorn K, Ofek I. Collectins and pulmonary innate immunity. Immunol Rev. 2000;173:52-65.

8. Hartshorn KL, White MR, Shepherd V, Reid K, Jensenius JC, Crouch EC: Mechanisms of anti-influenza activity of surfactant proteins A and D: comparison with serum collectins. Am J Physiol 1997;273:L1156-L1166.

9. LeVine AM, Elliott J, Whitsett JA, Srikiatkhachorn A, Crouch E, DeSilva N, Korfhagen T: Surfactant protein-D enhances phagocytosis and pulmonary clearance of respiratory syncytial virus. Am J Respir Cell Mol Biol 2004;31:193-199.

10. LeVine AM, Whitsett JA, Gwozdz JA, Richardson TR, Fisher JH, Burhans MS, Korfhagen TR: Distinct effects of surfactant protein A or D deficiency during bacterial of type 2 pneumocytes and thus increase the production of surfactant proteins and enzymes necessary for phospholipid synthesis. Corticosteroids also induce pulmonary $\beta$-receptors, which play a role in surfactant release and alveolar fluid absorption when stimulated (34). These observations suggest the possibility that surfactant or its stimulants be used to modulate immune responses during inflammatory lung disease like tuberculosis, but further studies are necessary.

infection on the lung. J Immunol (Baltimore, Md: 1950) 2000;165:3934-3940.

11. LeVine AM, Whitsett JA, Hartshorn KL, Crouch EC, Korfhagen TR: Surfactant protein D enhances clearance of influenza A virus from the lung in vivo. J Immunol (Baltimore, Md: 1950) 2001;167:5868-5873.

12. Ferguson JS, Martin JL, Azad AK, McCarthy TR, Kang PB, Voelker DR, Crouch EC, Schlesinger LS: Surfactant protein D increases fusion of Mycobacterium tuberculosis-containing phagosomes with lysosomes in human macrophages. Infect Immun 2006;74:70057009 .

13. Gaynor CD, McCormack FX, Voelker DR, McGowan SE, Schlesinger LS: Pulmonary surfactant protein A mediates enhanced phagocytosis of Mycobacterium tuberculosis by a direct interaction with human macrophages. J Immunol (Baltimore, Md: 1950) 1995;155:5343-5351.

14. Ghildyal R, Hartley C, Varrasso A, Meanger J, Voelker DR, Anders EM, Mills J: Surfactant protein A binds to the fusion glycoprotein of respiratory syncytial virus and neutralizes virion infectivity. J Infect Dis 1999;180:2009-2013.

15. Madan T, Eggleton P, Kishore U, Strong P, Aggrawal SS, Sarma PU, Reid KB: Binding of pulmonary surfactant proteins $A$ and $D$ to Aspergillus fumigatus conidia enhances phagocytosis and killing by human neutrophils and alveolar macrophages. Infect Immun 1997;65:3171-3179.

16. Thawer S, Auret J, Schnoeller C, Chetty A, Smith K, Darby M, Roberts L, Mackay RM, Whitwell HJ, Timms JF, Madsen J, Selkirk ME, Brombacher F, Clark HW, Horsnell WG: Surfactant protein-D is essential for immunity to helminth infection. PLoS Pathogens 2016;12:e1005461.

17. Wright JR: Immunoregulatory functions of surfactant proteins. Nat Rev Immunol 2005;5:58-68. 
18. Kishore U, Greenhough TJ, Waters P, Shrive AK, Ghai R, Kamran MF, Bernal $\mathrm{AL}$, Reid KB, Madan T, Chakraborty $\mathrm{T}$ : Surfactant proteins SP-A and SP-D: structure, function and receptors. Mol Immunol 2006;43:1293-1315.

19. Jäkel A, Qaseem AS, Kishore U, Sim RB: Ligands and receptors of lung surfactant proteins SP-A and SP-D. Front Biosci (Landmark Ed) 2013;18:1129-1140.

20. Ige O, Edem V.F and Arinola O.G. Plasma adenosine deaminase enzyme reduces with treatment of pulmonary tuberculosis in Nigerian patients: Indication for diagnosis and treatment monitoring. Nigerian Journal Of Physiological Science. 2016; 31(1): 49-53.

21. Manabe YC, Dannenberg Jr. AM, Tyagi, S.K, Hatem C.L, Yoder M, Woolwine SC,Zook BC, Pitt ML and Bishai WR. Different Strains of Mycobacterium tuberculosis Cause Various Spectrums of Disease in the Rabbit Model of Tuberculosis. Infect Immun. 2003; 71(10): 6004-6011.

22. Lin Z, deMello D, Phelps DS, Koltun WA, Page M, Floros J: Both human SP-A1 and $\mathrm{Sp}-\mathrm{A} 2$ genes are expressed in small and large intestine. Pediatr Pathol Mol Med 2001;20:367-386.

23. Jeffrey A. Gold, Yoshihiko Hoshino, Naohiko Tanaka, William N. Rom, Bindu Raju, Rany Condos and Michael D. Weiden. Surfactant Protein A Modulates the Inflammatory Response in Macrophages during Tuberculosis. Infect. Immun. February 2004 vol. 72 no. 2 645650

24. Head JF, Mealy TR, McCormack FX, Seaton BA: Crystal structure of trimeric carbohydrate recognition and neck domains of surfactant protein A. J Biol Chem 2003;278:43254-43260.

25. Zhang P, McAlinden A, Li S, Schumacher T, Wang H, Hu S, Sandell L, Crouch E: The amino-terminal heptad repeats of the coiled-coil neck domain of pulmonary surfactant protein D are necessary for the assembly of trimeric subunits and dodecamers. J Biol Chem 2001;276:1986219870.
26. Hawgood, S., et al. Sequential targeted deficiency of SP-A and -D leads to progressive alveolar lipoproteinosis and emphysema. Am. J. Physiol. Lung Cell. Mol. Physiol. 2002; 283:L1002-L1010.

27. Hall-Stoodley, L., et al. Mycobacterium tuberculosis binding to human surfactant proteins $\mathrm{A}$ and $\mathrm{D}$, fibronectin, and small airway epithelial cells under shear conditions. Infect. Immun. 2006; 74:35873596.

28. Sidobre, S., J. Nigou, G. Puzo, and M. Riviere. Lipoglycans are putative ligands for the human pulmonary surfactant protein A attachment to mycobacteria. Critical role of the lipids for lectin-carbohydrate recognition. J. Biol. Chem. 2007; 275:2415-2422.

29. Pasula, R., et al. Surfactant protein A (SPA) mediates attachment of Mycobacterium tuberculosis to murine alveolar macrophages. Am. J. Respir. Cell Mol. Biol. 1997. 17:209-217.

30. Ragas, A., L. Roussel, G. Puzo, and M. Riviere. The Mycobacterium tuberculosis cell-surface glycoprotein apa as a potential adhesin to colonize target cells via the innate immune system pulmonary C-type lectin surfactant protein A. J. Biol. Chem.2007; 282:5133-5142.

31. Torrelles, J. B., A. K. Azad, L. N. Henning, T. K. Carlson, and L. S. Schlesinger. Role of C-type lectins in mycobacterial infections. Curr. Drug Targets. 2008; 9:102112.

32. Antal JM, Divis LT, Erzurum SC, Wiedema nn HP, Thomassen MJ. Surfactant suppresses NF-kappa B activation in human monocytic cells. Am J Respir Cell Mol Biol 1996;14:374-379.

33. Birkun AA, Kubyshkin AV, Novikov NY, Krivorutchenko YL, Fedosov MI, Postniko va ON, Snitser AA. Joint intratracheal surfactant-antibacterial therapy in experimental Pseudomonas-induced pneumonia. J Aerosol Med Pulm Drug Deliv [online ahead of print] 17 Dec 2014; DOI:10.1089/jamp.2014.1161

34. Ballard PL, Ballard RA. Scientific basis and therapeutic regimens for use of antenatal glucocorticoids. Am J Obstet Gynecol 1995;173:254-262. 